\title{
Mito, logos y religión en Walter Benjamin
}

\author{
Reyes Mate
}

\begin{abstract}
$\mathbf{I}$

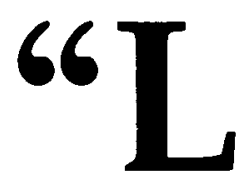

as citas en mi obra son como salteadores de caminos que asaltan violentamente y limpian de todo convencimiento a los pacíficos paseantes". ${ }^{1}$ En esta mil veces citada frase de Benjamin se pone al descubierto su original relación
\end{abstract} con textos del pasado. No se los toma por auctoritates capaces de dar el visto bueno a lo que uno piensa o escribe de ellos (que es lo que habitualmente hacemos todos) sino que él, Benjamin, se permite entrar a saco en el pasado, arrancando el texto de su contexto y dejándole en libertad para que le susurre a él un sentido escondido e inédito.

Si en esa frase Benjamin desvela su propia hermeneútica respecto a otros textos o autores, malo sería que lo olvidáramos a la hora de enfrentarnos a los suyos. Es indudable que asistimos a una ola benjaminiana: se multiplican los encuentros, se llenan las librerías de libros sobre Benjamin, siguen las traducciones; todos sus escritos, papeles de trabajo, borradores, han acabado conformando unas obras completas que se venden en ediciones de bolsillo... Es difícil, sin embargo, no percibir en todo este "boom benjaminístico" un sabor escolaticista. Está en juego acertar con la "ipssisima significatio", de ahí esos torneos eruditos en los que se acumulan citas a destaio, y donde importa sorprender al otro con una frase todavía más rebuscada y brillante que la anterior. No es esa mi intención. Para ser fiel a la infidelidad hermenéutica que él decía a propósito de la cita lo que importa no es hablar de Benjamin sino dejarle hablar. Es decir, importa señalar de entrada desde qué contexto nuevo y contemporáneo uno quiere entrar en diálogo con Benjamin. Puesto que el "Sitz im Leben" es nuevo, es

1 "Zitate in meiner Arheit sind wie Räuber am Wege, die bewaffnet hervorbrechen und dem Müssiggänger die Uberzeugung abnehmen", W. Benjamin, Gesammelte Scbriften, Suhrkamp, Frankfurt, 1991, V 138, (en actelante GS). 
el nuestro, nada tiene de extraño que Benjamin diga algo que hasta ahora hubiera callado. $\mathrm{O}$, dicho en otras palabras menos pretenciosas: es posible que aquí y ahora sus textos destilen un significado al que no tuvieron acceso sus propios amigos o las generaciones inmediatamente siguientes. ${ }^{2}$ Esta afirmación de que nosotros hoy podemos entender a Rousseau, por ejemplo, mejor que sus propios contemporáneos no es una bravuconada sino consecuencia de la convicción hermenéutica según la cual el texto tiene su vida propia, más allá del contexto de origen al que se refiere la "auctoritas".

Importa pues dejar bien claro la disposición con la que nos acercamos a los textos de Benjamin. Esa disposición queda manifiesta en el interés por su lectura: hoy sentimos que hemos perdido pie, que el bumus cultural en el que se desenvolvían nuestras certezas y perplejidades está resquebrajado. No es que no acertemos con las respuestas a nuestros problemas, es que no damos en formular los propios problemas. Se trata de escuchar el pasado para hacernos una idea aproximada de nuestra menesterosidad. La palabra de Benjamin quizás ayude a conformar algo así como un tema de nuestro tiempo.

\section{II}

Ronda hoy a la sociedad un asunto que no dejó de preocupar a Benjamin: la relación entre el mito y la razón. Más aún, podemos decir que éste fue el tema mayor, en un determinado momento, de la Escuela de Frankfurt, tal y como queda reflejado en ese misterioso libro llamado Dialektik der Aufklärung. La confesión de que algo hay en el mito que lleva hacia la Ilustración, aunque más verdad es que la Ilustración se hunde cada vez más en el mito ${ }^{3}$ no es, como se verá, una frase marginal sino que recoge la desesperanzada tesis fundamental del célebre libro.

En este final de siglo crece el interés por el mito. No se trata sin embargo de la enésima "vuelta al mito". Hoy se habla de una apología del polimitismo, dando a entender con ello que el interés actual por el mito es nuevo: no se hace a espaldas del desencantamiento que enterró a los dioses sino a partir de él; y no habla del mito, sino de los mitos. Son dos diferencias substanciales.

2 "Manche Seite bei Marivaux oder bei Rousseau weist einen geheimen Sinn auf, den die zeitgenössichen Leser nicht voll haben entziffern können", GS I 3, 1238.

3 "Wie die Mythen schon Aufklärung vollziehen, so verstrickt Aufklärung mit jedem ihrer Schritte tiefer sich in Mythologie", en Horkheimer-Adorno Dialektik der Aufklänung, Querido Verlag, Amsterdam 1947, 22 (en adelante DA). Sobre la influencia que tuvo Benjamin en su concepción, $c f$. R. Wiggershaus Die Franfurter Schule, DTV Wissenschaft, München 1988, 348 y ss. 
Intentemos pues fijar la posición del polimitismo. ${ }^{4}$ Una rápida mirada a la filosofía contemporánea nos permite distinguir dos talantes ante el mito. Por un lado, aquellos partidarios de la razón para los que la Ilustración es precisamente un proceso de secularización, es decir, de desmitologización, de tal suerte que el mito es aquello de lo que hay que alejarse si se trata de conceptualizar la realidad. Que unos celebren ese proceso (desde Comte a Horkheimer-Adorno) o que otros lo lamenten (como Vico o Heidegger) en nada afecta el reconocimiento general de que el logo se instala en la razón cuando se desprende del mito. Otros, sin embargo, dudan que la cosa haya sido así: no hay manera de desentenderse del mito y la prueba más fehaciente es la caída en el mito de la propia Ilustración. Para los Lévy-Strauss, H. Blumenberg, L. Kolakowski y el propio O. Maquard fuerza es reconocer que el hombre no puede vivir sin mitos.

Como se puede ver, el polimitismo no se sustenta en nombres anti o premodernos, sino en filósofos de la modernidad para los que sin embargo la filosofía clásica con sus pretensiones universales sobre la verdad y la bondad se ha consumado sin poder dar las respuestas que pretendía. Por eso el Polimitismo avanza con la bandera desplegada del adiós a lo que hasta ahora parecía substantivo: hay que olvidarse de las grandes palabras que tanto gustaban a la filosofia, díganse verdad o ética. Precisamente esta pretensión sustitutoria o hereditaria —el polimitismo quiere quedarse con la herencia de la filosofía- es lo que obliga a emplearse a fondo. La disputa por la herencia filosófica es un combate en torno a la verdad y a la ética. Esto quiere decir que el interés actual por el mito es nuevo pues no se para en una reconstrucción romántica del mito, ni le interesa el potencial movilizador del mito ni su función compensatoria respecto a una razón más o menos ocupada en negocios científicos. "La Loa del Polimitismo", tal y como resume J. Taubes, "se produce en el preciso instante en el que se produce la crisis de la filosofía y de la historia y en el horizonte de la autodescomposición de la filosofia, anunciada por Hegel y Marx, en el contexto de la Teoría y Praxis del marxismo". 5 Es un desafío substantivo que responde a un "estado de ánimo" de nuestra sociedad que bien podríamos calificar de "mitógeno", en contraposición a momentos anteriores que se fiaban más del poder creador del logos ("logógeno").

El lugar, pues, desde el que nos vamos a referir a Walter Benjamin es el del abandono o finiquito de las preguntas por la verdad y el bien en

4 Cf. O. Marquard, Ahscbied vom Prinzipiellen, Reclam, Stuttgart 1991.

5 Cf. J. Taubes, "Zur Konjunktur des Polytheismus", en Mytbos un Moderne, hrsg. v. K. H. Bohrer, Suhrkamp, Frankfur, 459. 
nombre del mito. Los nuevos apologetas saben que ésta fue una cuestión central a la DA y al propio Benjamin, aunque los susodichos apologetas se presentan con una oferta capaz de recorrer el laberinto en el que se perdieron aquellos ilustrados.

\section{III}

En algún momento - y no parece que haya que dilatarlo más- hay que preguntarse qué se entiende por mito. Odo Maquard, por ejemplo, remite a Aristóteles, que a sí mismo se tomaba por un "mitófilo", esto és, alguien que gustosamente escuchaba historias. Los mitos son bistorias, historias que se cuentan y que se oyen. Por eso quien pretenda negar el mito tendrá que acabar con las historias. Claro que cabe preguntarse qué tienen que ver las historias contadas en leyendas, fábulas, cuentos o novelas con la verdad. ¿Acaso no callan las fabulaciones cuando se expone con objetividad la verdad de los hechos? Quien se creyera eso tomaría al mito por el umbral de la verdad. Nada de eso: el mito es el arte de integrar la verdad en el vasto mundo de la vida.

Se puede y se debe distinguir entre saber de la ciencia y las historias del mito. El saber tiene que habérselas con la verdad y el error, en tanto que el mito, con la felicidad y la infelicidad. No son dos momentos del mismo proceso, ordenados jerárquicamente (el mito como pre-historia del logos, pudiendo sólo éste constituir la verdadera "historia"), sino distintos procesos con la misma cita: en el vivir concreto.

No perdamos de vista que estamos en contexto ilustrado, es decir, no se trata de una conversión indiscriminada al mito. Tal vuelta no lo soportaria la Ilustración. La conciencia ilustrada, en efecto, es la que discrimina entre los mitos que, como entre las setas, los hay buenos y malos. Malo es el monomito y bueno, el polimitismo. Sólo este último garantiza la libertad y la individualidad. Quien participa, en efecto, de muchas historias sólo se sentirá parcialmente identificado con cada una de ellas y entre unas y otras encuentra el espacio libre para la libre decisión. Quien, por el contrario, sólo se atiene a una historia tendrá que seguirla, al precio de atrofia narrativa. Pagará la fidelidad al monomito con "una identidad sin libertad por no tener la posibilidad de perder la identidad". 6

Como se ve el concepto discriminador entre mitos buenos y malos es el de la libertad. Todo mito conlleva poder, pero lo propio del polimitismo es la "división de poderes". De ahí su garantía de libertad.

6 "Unfreiheit der Identität aus Mangel an Nichtidentität", dice O. Marquard en Abscbied vom Prinzipiellen, 98. 
Cuando se habla de monomito no se está pensando en el Dios abrahámico sino en su versión contemporánea: el mito del progreso, de la filosofia de la historia o de la revolución. ${ }^{7}$ El mito del progreso imparable de la humanidad hacia la libertad, anunciado por la filosofia de la historia de la emancipación revolucionaria, ha sido un engendro de la Razón fabricado con nocturnidad y alevosía en el siglo xviI, comprimiendo por la fuerza las libertades en libertad y las historias en historia. Esta Razón que empezó exigiendo el sacrificium mithorum se cobró luego el sacrificium essentiae, esto es, la substancia del mundo. Las filosofias revolucionarias de la historia son "historias sagradas" que privan de sentido la realidad presente trasladándole a un futuro que advendrá. Se consigue así que la realidad del mundo presente quede privada del sentido que da la historia, a merced por tanto de la voracidad de las ciencias exactas. La bienintencionada "historia sagrada" acaba así privando de historia a la realidad concreta. El monomito desmitifica al mundo vaciándole de historias y de ese mundo da cuenta el positivismo científico que, celoso de su territorio, cuelga el sambenito de la superstición sobre la historia.

El monomito, pues, coloca a la realidad presente en la órbita de una "historia sagrada", lo que lleva inevitablemente a privar el presente de toda historia. Para Hans Blumenberg esta situación revela la naturaleza propia del monomito contemporáneo: el mito gnóstico. ${ }^{8}$

Blumenberg es, como se sabe, el defensor de una teoría de la legitimidad de los tiempos modernos frontalmente enfrentada a las tan extendidas y aceptadas teorías de la secularización. Quienes defienden que el mundo moderno es una "secularización" del mundo cristiano, ejercen un subliminal "embargo" sobre la modernidad al recordarle a ésta que no tiene más substancia que la heredada de la religión. Para Blumenberg, por el contrario, el paso del mundo cristiano-medieval al mundo moderno no es el de un escanciamiento de verdades teológicas en moldes laicos, sino la sustitución de una cultura, con sus preguntas y respuestas, por otra. ${ }^{9}$

La cultura moderna sería heredera de una tradición secularmente enfrentada al mito gnóstico. in pretender ahora una exposición exhaustiva del gnosticismo podríanıos acordar que el gnosticismo actualiza los rasgos más radicales de la escatología cristiana: que el mundo es malo y

7 "der Mythos des unaufhaltsamen weltgesellschaftlichen Fortschritts zur Freiheit der Geschichtsphilosophie der revolutionären Emanzipation", en O. Marquard, o.c. 99.

- Cf. O. Marquard "das gnostische Rezidiv als Gegenneuzeit" en Religions und politische Theologie, hrsg. v. I. Taubes, Fink Verlag, München 1984, Bd. 2, 31-36.

9 Cf. Les deux tisages de la théologie de la sécularisation editado por M. Xhaufflaire, Casterman, Tournai 1970, 81. 
sólo puede ser salvado con su acabamiento, gracias a la inminente vuelta del Señor. El gnosticismo aparece en el momento en que la comunidad empieza a desesperarse porque esa venida no se produce. El gnosticismo ofrece una doble salida: a) huida hacia el interior de uno mismo, desentendiéndose del mundo malo y b) construcción de un modelo maniqueo que asigna un Principio al Bien y otro al Mal.

Marcion y Agustín de Hipona son los protagonistas del primer enfrentamiento entre el gnosticismo y la tradición moderna. Marcion, en efecto, concreta al Principio del Bien en el Dios Salvador y el Principio del $\mathrm{Mal}$, en el Dios Creador. El mundo creado sería al escenario del mal que sólo tendría arreglo mediante su exterminio por el Salvador que vendrá. san Agustín también se enfrenta al problema del mal en el mundo pero no lo resuelve maniqueamente sino "antropologizándole": el mundo no es malo, ni hay un Principio del Mal; el problema del mal es un problema de la libertad del hombre. ${ }^{10}$

El segundo episodio corre a cargo del nominalismo y la modernidad. El nominalismo, celoso de la libertad del hombre, cercena su "Übelbewirkungsfähigkeit" (su capacidad de generar mal), colocando por encima de esa capacidad el principio de un Dios Creador. Dios, dotado de "potentia absoluta", niega el mundo en tanto en cuanto niega todo lo que en él limite su omnímoda libertad. Ese sería el fondo de la negación de los "universales" que eran como el emblema de la soberanía de los entes, el distintivo que señalaba que los entes tenían unas características definidas, que ni Dios podría alterar y que estaban a disposición del conocimiento humano. El "absolutismo teológico" no podía soportar esa limitación de Dios, de ahí la negación de los "universales", que era negar la autonomía del mundo. Estamos ante el segundo triunfo del gnosticismo mediante el nominalismo ya que su "negación del mundo es la afirmación de un Dios extraño al mundo"."11

La Modernidad supone una nueva superación del gnosticismo. Se trata ahora de la afirmación del mundo mediante la negación de la divinidad que le es hostil y extraña. Esto lo hace la modernidad mediante una estrategia de neutralización de la escatologia. Primero se inventa el Estado cuya sola existencia anuncia la consistencia del mundo, aunque carezca

10 Para Metz san Agustín descubre la libertad del hombre y acaba con la "Theodizeefrage", pues exculpa a Dios y al mundo. Dios nada tiene que ver con el mal -nueva muerte de Job- y el mundo como mundo, es decir, como historia, tampoco. El problema del mal es el problema del "pecado", $c f$. "Die Rede von Gott angesichts der Leidensgeschichte der Welt", en: Stimmen Der Zeit, Heft 5, Mai 1992, 311-320.

11 O. Maquard, "Das gnostiche Rezidiv als Gegenneuzeit", 33. 
de un plan de salvación. Luego viene la neutralización de la escatología mediante la ciencia, la economía, la técnica... En efecto, mientras la realidad se configure en un Estado y se interprete científica, económica, o técnicamente, no habrá por qué recurrir a un sentido o a una salvación que venga de fuera o que se dé en el futuro. Esa estrategia neutralizadora es la Ilustración.

Esta estrategia neutralizadora desdramatiza los problemas de la vida que pasan a ser si no banales sí al menos circunstancias desprovistas de la carga épica que tenían hasta entonces. Esta naturalización de las circunstancias vitales, propias de la Ilustración, conllevaban un "déficit" motivacional. Nada extraño pues que se busque compensar esa carencia mediante excitaciones salvíficas, mediante una fuerte moralización que someta la suerte de la realidad inmediata al destino de decisiones extrasubjetivas. De esta manera se desneutraliza la Modernidad y se recupera la escatología, ahora sí secularizada. Es la hora de las filosofias revolucionarias de la historia.

Estamos ante un nuevo triunfo del gnosticismo. Poco importa que el mito gnóstico se revista ahora de negación de Dios. La "muerte de Dios", expresada en la letra de las filosofias de la historia que subrayan la afirmación del mundo contra el Dios que lo negaba, esa "muerte de Dios" de hecho se articula en una nueva negación del mundo gracias a una nueva afirmación de la inanidad del mundo: la realidad presente y el hombre concreto están bajo sospecha y sólo serán redimidos y liberados mediante la Revolución que es la negación del presente y la afirmación de lo ausente. Como en el caso de Marcion, el mundo presente es malo y sólo se salvará con su acabamiento.

El monomito de la razón ilustrada y el mito gnóstico de las filosofias salvíficas de la historia acaban anulando al hombre concreto que tan bien se las bandeaba en el politeísmo y que tuvo su edad de oro en la Modernidad. Nada extraño que el hombre medio contemporáneo - sobre todo la juventud- exprese su angustia con el gusto por lo exótico y lo arcaico. Es el síntoma de una carencia (de sentido del presente), pero ninguna solución ya que esas "salidas" tienen que articularse en el monomito dominante.

\section{IV}

La decisión no es pues entre mito y logos sino entre mito y mitos. Quizá convenga recordar que ya en 1880 , el autor del "Älteste Systemprogram des deutschen Idealismus" confesaba que "nosotros tenemos que tener una mitología, a saber, una mitología de la razón". Y puesto que el mito 
es inevitable, se opta consecuentemente por el polimitismo ya que el mito de verdad es lógicamente politeísta. ${ }^{12}$

Estamos pues ante un "alegato por un polimitismo ilustrado". El matiz ilustrado del mito se concreta en dos puntos. Por un lado, el moderno polimitismo toma de la Ilustración la crítica a la violencia que ejerce el sino (mito preilustrado) sobre el destino individual. Dicho en otras palabras: la pluralidad de mitos crea "ese mínimo de caos que es la condición de posibilidad de la individualidad". No se quiere decir que el individuo sea una creatura del polimitismo —es más bien del monoteísmo, aunque por reacción. Lo que se quiere decir es que una vez conquistada la individualidad es en el polimitismo donde puede desarrollarla eficazmente. Pero, por otro, esa exigencia de libertad, tan ilustrada ella, sólo es articulable desde el polimitismo. Hoy sabemos que el ejercicio de la libertad, en sociedades tan complejas como las nuestras, exige una división de poderes. Ahora bien, esa división no comienza con la razón, sino con los dioses. Dice Marquard: "La moderna cristalización del politeísmo —que es profana e inmanente- es la división política de poderes: es el politeísmo ilustrado y secularizado. Tal división no comienza con Montesquieu, Locke o Aristóteles. Comienza con el politeísmo: como división de poderes en el Olimpo mediante el pluralismo de los dioses". ${ }^{13}$ Así pues, en el polimitismo están dadas y garantizadas las distintas formas de división de poderes: la clásica división entre legislativo, judicial y ejecutivo y otras como el federalismo, las teorias del disenso o la libre competencia de fuerzas económicas en el mercado. ${ }^{14}$

Estamos pues ante una estrategia cultural empeñada en cohonestar mito con logos de una manera civilizada. Ya se puede citar, sin miedo alguno, la antigua previsión de Max Weber de que "los muchos y viejos dioses, ahora ya desencantados y en la figura de fuerzas anónimas, salen de sus tumbas, pujan por el poder sobre nuestras vidas y vuelven de nuevo a sus viejas peleas". ${ }^{15}$ Como se ve el polimitismo basa su fuerza argumentativa

12 "Jeder Mythos politeistisch ist" dice C. Schmitt, "die politische Theorie des Mythos", en Positionen und Begriffe: im Kampf mit Weimar-Versailles, 1923-1939, Berlin 1988, Duncker und Humbolt, p. 17.

13 O. Maquard, Abschied vom Prinzipiellen, 53-54.

$14 \mathrm{R}$. Faber cuestiona radicalmente las ideas que Marquard se hace de los dioses antiguos. Los dioses homéricos son seres oligárquicos, semejantes a aquellos jefes griegos que declararon una guerra de exterminio contra Troya. Y anade: "El Politeísmo es un Oligoteismo que como tal es consciente de su propio ocaso". Cf. R. Faber "Von der Erledigung jeder polithischen Theologie zur Konstituion politischer Polytheologie", en: Taubes, hrsg, Religionstheorie und politische Theologie, Bd. 1, 96.

${ }^{15} \mathrm{M}$. Weber, "Wissenschaft als Beruf", en Gesammelte Aufsätze zur Wissenschaftslebre, J.C.B. Mohr, Tübingen 1968, 605 y ss. 
en la garantía de la libertad moderna, herencia mayor de la modernidad. Cabe preguntarse en todo caso de qué libertad estamos hablando. No ya de la libertad ilustrada, aquélla que ligaba los conceptos de verdad y libertad, sino de una libertad entendida ahora como pura indeterminación.

\section{$\mathbf{V}$}

Cuando el polimitismo no ceja de repetir el carácter "ilustrado" y "secular" de la vuelta al mito ("del culto a la biblioteca", dicen) es porque saben perfectamente que el problema llustración-mito es un asunto consubstancial e inconcluso de la "dialéctica de la Ilustración".

Desde la introducción al libro los autores de la DA dejan bien sentado que el meollo crítico del libro "se agrupa en torno a dos tesis: que ya el mito es Ilustración y que la Ilustración recae en el mito". ${ }^{16}$ Con esta presentación, que suena a declaración de principios, los "ilustrados" Horkheimer y Adorno se alejan de la opinión generalizada según la cual La Ilustración sería lo opuesto al mito (a la fuerza del sino la Ilustración opondría la fuerza del razonamiento) y su antídoto (a "inconsciente colectivo", caldo de cultivo del mito, conocimiento individual). Esa alternativa no se ajusta a los hechos que nadan, por el contrario, en las confusas aguas mitológicas. Para apoyar su tesis dedican un largo excuso a la dialéctica entre mito e Ilustración en la Odisea.

La Odisea es una mitología, es decir, una agrupación de relatos míticos. Pero es también el testimonio de la huída del sujeto de la órbita mítica $y$, en este sentido, un testimonio madrugador de la subjetividad humana. La Odisea pone en evidencia algo así como una "dialéctica entre el mito y el logos": por un lado, en efecto, queda bien expresada la necesidad que tiene toda conciencia colectiva de referirse al origen, si quiere estar viva; claro que, por otro lado, esa fidelidad al origen, esa necesidad de repristinación ha de hacerse del tal manera que el sujeto consiga liberarse de la atracción fatal originaria. La cara ilustrada de la citada dialéctica consistiría en la capacidad de liberarse de la seducción original; ése sería su momento emancipador. La cara mítica, por el contrario, estribaría en la querencia del sujeto por el origen que anularía todo intento emancipador.

Pues bien, la conclusión que sacan los autores de la DA de su lectura de la Odisea es que no hay manera de librarse de la seducción mítica. De esta suerte la dialéctica entre el mito y el logos se resuelve en una círculo infernal que aborta la emancipación humana. Esto queda particularmente claro en la explicación del relato del canto de las Sirenas. Recordemos la

${ }^{16}$ Horkheimer-Adorno, DA, 10. 
escena: Circe aconseja a Odiseo que para escapar a la atracción letal del canto de las sirenas debería tapar con cera los oídos de sus acompañantes y él, si quería oírlas, tendría que dejarse previamente amarrar al mástil del barco y ordenar a su gente que por nada del mundo le soltaran. Y así, con astucia y engaño, consigue vencer la seducción del mito.

Ahora bien, ¿es eso liberación y superación del mito? En absoluto. La astucia no vence al encanto del mito, sólo le sortea, trampea con él, pero sin poder romper la órbita de poder del mito. El hombre, con su astucia, sólo logra sobrevivir pero dejándose sus sueños en el camino. Nunca consigue todo lo que quiere pues constantemente tiene que renunciar a sus deseos o bailar al son que tocan: por eso se dice a sí mismo que tiene que ser paciente y no comer el rico ganado del divino Hyperion; y si se empeña en seguir adelante tendrá que aceptar pagar con la muerte de sus acompañantes el precio del paso entre Escila y Caribdis. Para sobrevivir tiene que aguantarse y si otros traducen "sobrevivir a tanto infortunio" por fama, él bien sabe que "la dignidad de héroe sólo se consigue en tanto en cuanto uno sacrifica la exigencia a la felicidad toda, para todos indistintamente". ${ }^{17}$

Ia Odisea pone en evidencia que el hombre tiene que sacrificar lo que hay de vital en sí mismo para poder salvar un yo petrificado.

El relato de la Odisea - que para Horkheimer es el primer documento de una Antropología en el sentido moderno, es decir, de un hombre racionalmente ilustrado - ejemplifica bien las dos tesis fundamentales de partida: a) "que ya el mito es ilustración", aspecto bien visible en la voluntad de Odiseo de cumplir su plan, a pesar de la oposición de fuerzas mayores y b) "que la Ilustración vuelve al mito": a esas "fuerzas mayores" uno las puede driblar con ingenio pero no las vence $\mathrm{y}$, por tanto, no escapa uno de ellas.

No olvidemos que la DA no es un ensayo interpretativo de mitos griegos sino que pretende ser un diagnóstico de la situación actual. La Odisea presta lenguaje - conceptos y categorías- para explicar la situación actual. Y al ahora se refieren las dos tesis anteriormente citadas: "Que

17 "Der Listige überlebt nur um den Preis seines eigenen Traums, den er abdingt, indem er wie die Gewvalten draussen sich selbst entzaubert. Er eben kann nie das Ganze haben, er muss immer wartèn können, Geduld haben, verzichten, er darf nicht vom Lotos essen und nicht von den Rinden des heiligen Hyperion, und wenn er durch die Meerenge steuert, muss er den Verlust der Gefährten einkalkulieren, welche Szilla aus dem Schiff reiss. Er windet sich durch, das ist sein Überleben, und aller Ruhm, den er selbst und die andren ihm dabei gewähren, bestätigt bloss, dass die Heroenwürde nur gewonnen wird, inden der Drang zum ganzen, algemeinen, ungeteilten Glück sich demütigt", en HorkheimerAdorno, DA, 74. 
el mito es ilustración y que la ilustración revierte en mito". El acento se pone ahora en el carácter mítico de la famosa Ilustración. Y así es.

La Ilustración se presenta históricamente como el dominio del hombre de las fuerzas extrañas al mismo, sean éstas míticas o naturales. Se corona todo un proceso histórico en el que la naturaleza más parecía algo habitado por fuerzas incontrolables; ahora sin embargo se nos manifiesta como algo sometido a leyes que el hombre conoce y al directo dominio del hombre. Pero si bien se miran las cosas se verá que, pese al dominio, el hombre no ha roto su maleficio pues esa naturaleza sobrevive en él de una forma nueva: apoderándose de su racionalidad. La ilustración debería inaugurar, con el triunfo del hombre sobre los poderes míticos, el dominio sobre sí mismo puesto que nadie fuera de él le es superior. Pero curiosamente ese dominio soberano del hombre es virtualmente la negación de ese sujeto en cuyo provecho él ha librado la batalla contra las furias míticas; resulta en efecto que la técnica del dominio del hombre sobre la naturaleza no es neutra sino que exige un sacrificio del propio sujeto: le exige sacrificar lo que él tiene de más vital (esa "exigencia a la felicidad toda, para todos e indistintamente") de tal suerte que lo que debería ser conservado por el dominio soberano del hombre es lo que se deja en el camino. ${ }^{18}$

Tal y como demuestra la Odisea la Ilustración es una tarea imposible $o$, si se prefiere, la Ilustración es un episodio dentro de una trama que no es ilustrada. ${ }^{19}$

\section{VI}

Ahora se puede calibrar mejor la actualidad de la vuelta al polimitismo. Sus defensores, en efecto, pretenden partir del punto en que lo deja la DA: que la Ilustración es un mito.

Lo que cambia sin embargo es el talante respecto a esa grave afirmación. Horkheimer y Adorno lo vivieron de una manera trágica. Detrás del mito y sobre el fracaso de la razón ellos veían caminar Los Cuatro

18 "Die Herrschaft des Menschen üher sich selbst, die sein Selbst begründet, ist virtuell allemanl die Vernichtung cles Subjekts, in dessen Dienst sie geschieht, denn die beherrschte, unterdruckte und durch Selbsterhaltung aufgelöst Substanz ist gar nichts anderes als das Lebendige, als dessen Funktion die Leistungen der Selhsterhaltung einzig sich bestimmen, eigentlich geracle das, was erhalten werclen soll", en HorkheimerAdorno, DA, 71.

19 ".... wo Aufklärung nur episodisch, nicht aber grundierenden Charakter gewinnwn kann", dice J. Taubes, "Zur Konjunktur des Polytheismus", en K.H. Bohrer, Hrsg., Mytbas und Modeme, Suhrkamp, 460. 
Jinetes del Apocalipsis. De ahí su pesimismo antropológico que no se tradujo, empero, por ningún nihilismo, como enseguida veremos. Ahora es diferente, como si el mito se hubiera aliviado de su carga mortal, en la primera mitad del siglo, y ahora apareciera con su cara buena, garante precisamente de lo que otrora aniquiló. Es la vuelta desencantada o ilustrada de los dioses que así, en plural, pueden liberarnos del terror de la razón y de la violencia del sino.

El polimitismo sería, en definitiva, una respuesta positiva a la desesperanza y a las aporías de la DA. Para ver el abismo que media entre el pesimismo de unos y el optimismo de otros, no parece ocioso detenernos un momento en las razones de los primeros.

Habermas se pregunta si la desesperanza de la DA no tiene que ver con una cierta ausencia de finura en el análisis histórico de la razón. ${ }^{20}$ Horkheimer y Adorno podrían, en efecto, haber valorado más ponderadamente la diferenciación de ámbitos de valor (ámbito metafísico, político o estético) como un gran logro en virtud del cual se ha creado una capacidad autocrítica de las ciencias, al tiempo que se han universalizado los derechos humanos en las diferentes Constituciones y se ha liberado la creatividad del arte, más allá de las convenciones y cánones empobrecedores.

Pero Horkheimer y Adorno han preferido ver el costo de la operación. Para ellos la diferenciación de ámbitos es la expresión, sí, de una voluntad de comprender cada ámbito desde la sola razón, pero olvidándose de la función unificadora de la misma, función unificadora que bebe del mito. Eso supone una escisión entre naturaleza y cultura, que se traduce de hecho en una desnaturalización del hombre y una deshumanización de la naturaleza. Por querer liberarse del mito la Ilustración ha dado de bruces en él pues esa razón pretendidamente autónoma está a merced de la querencia por el poder, que es lo que define al mito.

La cosa no deberia asustar. Al fin y al cabo la "dialéctica de la Ilustración" es consciente del peligro que amenaza constantemente a la razón y para eso está su crítica dispuesta a denunciar constantemente la caída de la razón en ideología. ¿Por qué la DA no da la batalla contra los abusos determinados de la razón en lugar de desacreditar totalmente a la razón? Pues porque para poder ejercer la crítica ideológica es necesario dar un voto de confianza a lo criticado, pese a la crítica. Era la confianza de Marx cuando escribe a A. Ruge en los Anales franco-alemanes: "Eso es la ventaja de la nueva línea: que nosotros no podemos anticipar dog-

20 J. Hahermas, "Die Verschlingung von Mythos und Aufklärung", en K.H. Bohrer, Hrsg., Mytbos und modeme. 409. 
máticamente el mundo, sino que tan sólo queremos encontrar el nuevo mundo a partir de la crítica al mundo viejo... No cabe la duda respecto a la tarea que tenemos que cumplir: me refiero a la critica sin contemplaciones de todo lo dado" ${ }^{21}$ Horkheimer y Adorno creyeron en los años treinta que lo nuevo nacería de los propios ideales burgueses, es decir, que la sociedad presente, pese a toda sus contradicciones, podía ofrecer una salida emancipadora; lo creyeron en los años treinta, pero no en los cuarenta. Entonces pensaron que el problema no era la "dialéctica" de la Ilustración sino la propia Ilustración. Ya no se plantean llevar la Ilustración a buen término sino impedir que se pierda definitivamente en el mito.

Este razonamiento, sin embargo, no deja de sorprender. Se proclama, sí, sin ambages el fracaso total de la razón pero no hasta el punto de no ser consciente de su fracaso. Es decir, la razón corrupta es consciente de su corrupción. Es una contradicción de la que ellos eran harto conscientes pues se fundaba en la débil fuerza ilustrada del mito; a ella se asian ellos desesperadamente porque la alternativa era el abismo. Un abismo por donde ahora ronda el polimitismo.

La alternativa, en efecto, era Nietzsche, cuya Genealogía de la moral fue algo más que un libro de cabecera de la DA. Nietzsche anuncia, en efecto, "la nada compasiva doctrina de la identidad entre poder y razón" (DA, 429), es decir, reconoce la identificación entre razón y poderío. Es un claro reconocimiento de la caída de la Ilustración en el mito. Nietzsche no se rebela ni se desesperanza con esta constatación. Al contrario, propone una consecuente teoria del poder cuyo primer principio reza así: abandonemos las clásicas "pretensiones de verdad" de la filosofía y sustituyámoslas por una "teoría estética". Se entiende lo que Nietzsche quiere decir con "teoría estética" cuando recordamos las contrafiguras de los nuevos valores estéticos: Jesús y Sócrates, el uno abogado de la creencia en el bien y en el mal y el otro, un apologeta de la verdad. La estética se sitúa más allá del bien y del mal, de lo verdadero y de lo falso. El órgano propio de este nuevo y trascendente conocimiento es el "gusto" cuyo es traducir los rancios "juicios de valor" por preferencias.

Ahora bien, si resulta que la verdad se resuelve es un asunto de gusto ¿es posible ya la crítica?; si la preferencia supone optar por algo y dejar o postergar lo otro ¿cuáles son los criterios de la preferencia?, ¿acaso no se supone un juicio de valor y, por tanto, una nueva referencia a la razón? No se trata de que entre por la ventana lo que se échó por la puerta. Ya sólo cabe distinguir entre un poder - no olvidemos que lo que está en causa es

${ }^{21}$ Marx-Engels, Sobre la religiōn I, Sigueme, Salamanca 1974, 428. 
una teoria del poder- que merece ser preferido y otro que merece ser preterido. Pues bien, el criterio de preferencia no es racional sino mítico. La preferencia la marca el "mito del origen": lo más ancestral, radical, es lo preferible. Como dice Habermas, "lo más antiguo es, en la cadena generacional, lo anterior, aquello que está más cerca del origen. Lo más originario es tomado por lo más digno, preferente, menos desgastado y más puro; es decir, vale por lo mejor. Nacimiento y origen son los criterios de la preferencia tanto en sentido social como lógico". ${ }^{22}$ La teoría del poderen cuestión no es una apología indiscriminada de todo poder: es preferible y por tanto "bueno", el más primario, que es también un poder "activo"; y será "malo", el más sofisticado, que es también un poder "reactivo".

Pues bien, Horkheimer y Adorno no siguen a Nietzsche hasta ese nihilismo radical; prefieren vivir con sus contradicciones a sabiendas de que nunca la Ilustración será una alternativa al mito. Nunca Odiseo escapará a la órbita mítica, lo que sí podrá sin embargo es ser consciente del peligro en el que vive $y$, eventualmente, sortearle. ${ }^{23}$

El fracaso de la razón o el triunfo del mito se salda con una teoría del poder. Eso lo sabían los autores de la DA, de ahí su radical pesimismo; eso lo saben los apologetas del polinitismo y no les preocupa, pues el problema no es ya el poder sino el poder absoluto. El politimismo se presenta precisamente como una "democratización" del poder. No se puede pasar por alto el lugar específico que ocupa Habermas, alguien preocupado de los mismos problemas pero equidistante de ambas posiciones. Habermas no participa ni del pesimismo de los unos ni del escepticismo cínico de los otros. ${ }^{24}$ Habermas piensa, en nombre de un análisis más riguroso de la historia social de la razón, que se puede apostar por el logos contra el mitos. La historia de la razón es la de la emancipación del mito. Y esa historia es la de la Ilustración. Ahí late el convencimiento de que hay un hiatus entre mito y logos, aunque no insalvable. ¿Escapará Habermas a la crítica de "desnaturalización del hombre" y de "deshumanización de la naturaleza" que los autores de la DA ubicaban precisamente en esa herida de la razón moderna?

22 Habermas, "Die Verschlingung...", 425.

${ }^{23}$ Eso se lo deben a Hegel, a su "bestimmte Negation", cf. Wiggerhaus, Die Frankfurter Schule, 360 .

24 Aqui vale lo que dice Horkheimer: "El escepticismo piercle su modo de ser racional cuando no se sobrepone y no se entrega conscientemente a su otro; cuando pierde la fe en las posibilidades concretas del hombre, Y esto ocurre cuando el escepticismo, en lugar de enfrentarse a los poderes dominantes del presente deja que sigan a su aire, mirándoles por encima del hombro; pues bien, un tal escepticismo ha perdido ya la cualidad de ser una figura del espiritu. Sólo se logra el yo cuando el yo lucha para que la humanidad se realice en su conjunto" Kritische Theorie II, Fischer Verlag, Frankfurt 1968, 234. 


\section{VII}

La postura de Walter Benjamin - anterior en el tiempo, no lo olvidemos, a la desesperanza de los unos, al cinismo de los otros y al optimismo racional de Habermas- es diferente de todas ellas. No renuncia a la "pretensión de verdad", como Horkheimer y Adorno, pero a diferencia de éstos no limita el problema de la verdad a un duelo entre el mito y la razón. El introduce un tercer elemento - la religión-que permite una salida a la DA distinta de los nuevos corifeos del polimitismo. Veamos.

a) Relación entre el mito y el logos.

No se les debe entender como dos conceptos alternativos, de suerte que, desde el punto de vista de la verdad, la afirmación de uno suponga la negación del otro.

El escrito de Benjamin sobre Kafka ${ }^{25}$ permite una excelente aproximación a la relación benjaminiana entre mito y logos. Kafka es celebrado por Benjamin como un "ilustrado cabal" y para demostrarlo se refiere a la interpretación kafkiana del mito en El silencio de la sirenas. Como se recordará Kafka enmienda la plana a Homero ya que en verdad Odiseo no escapa al embrujo de las sirenas por su astucia (recordemos: tapona los oídos de sus acompañantes para que no oigan nada y él pide ser amarrado al mástil). Lo que ocurrió sencillamente es que las sirenas se callaron. Lo que Kafka quiere dar a entender, según Benjamin, es que Kafka nada quiere saber del mito y opta de entrada por la desmitificación. Y no quiere saber nada del mito porque si nos colocamos ante el mito no hay manera de escapar de él. Odiseo no escapó y la razón autónoma que ha creido escapar sigue siendo su prisionera.

Ante el mal del mundo, de cuya inevitabilidad el mito es la expresión, no se lucha con músicas, astucias o huidas. Se lucha con la razón. De ahi que Kafka, "el nuevo Odiseo", sea celebrado como un ilustrado cabal ("untadeliger Aufklärer"). Benjamin estaría del lado de Habermas.

Pero la semblanza de Kafka no está concluida. Kafka es, además, un personaje mítico, un nuevo Sísifo que rueda hacia arriba el bloque del acontecer histórico; de esa manera consigue poner a la luz del día el lado tenebroso de la ilustración "que no resulta nacla grato a la visión, pero que Kafka aguanta perfectamente". Kafka resulta ser así la suma de Odiseo y de Sísifo. Su grandeza proviene de una doble fuente: a) es, como Odiseo,

25 "Das Recht hat in den Wek von Kafka den Charakter eines mythischen Gebildes", dice W. Benjamin en "Franz Kafka. Zur zehnten Wiederkehr seines Todestages", GS II, 1223; y cita una frase de K.: "... es gehört zu der Art dieses Gerichtswesens, dass man nicht nur unschuldig, sondern auch unwissend verurteilt wird", GS II 2, 412. 
un antimito, un "ilustrado" que se enfrenta a la realidad racionalmente, pero b) al igual que Sísifo sabe que lo del progreso incesante, que lo de la Ilustración, es una ilusión.

Benjamin no se queda a solas ni con Odiseo ni con Sísifo. El primero es un ingenuo ilustrado que está a merced del sino del mito y el segundo es un robot mecánico o mítico que no se ha planteado la posibilidad de la salvación.

Benjamin ya participa aquí del pesimismo propio de la DA sobre la Ilustración. Que la Ilustración sea un mito no ofrece dudas en Benjamin. Es verdad que la razón moderna ha supuesto un triunfo sobre la naturaleza y por tanto un triunfo sobre las fuerzas míticas. Pero el triunfo es aparente. Sobrevive en la modernidad lo que él llama "naturaleza irrebasable": el dominio racional somete a la naturaleza y la conforma desde sí mismo; ahora bien, esa naturaleza, conformada por la razón, sobrevive en la forma de un poder super-humano, contra el que el hombre vuelve a ser impotente. $Y$ en el escrito de Kafka Benjamin expone con detalle el carácter mítico de una de las creaciones más emblemáticas de la Modernidad: el derecho. El derecho moderno es mítico porque lo suyo es dictar sentencias sin saber lo que condena. Eso explica que no pueda bastarle el definir a Kafka como un ilustrado cabal. El mito de Sísifo, con su crítica de la Ilustración, completará la biografia intelectual de Kafka.

De lo dicho se desprende que la partida de la verdad no se juega de modo alternativo ("o uno u.otro") entre el mito y la razón. Ni es lo uno ni es lo otro; tampoco se trata de una dialéctica entre el mito y la razón, como quiere Habemas con su teoría de la profanación. ${ }^{26}$ Para que tal dialéctica fuera de recibo no tendría que darse ningún elemento más. Pero hay un tertium que también interviene en la partida de la verdad: la religión.

b) Relación entre el mito-logos y la religión.

La relación entre mito y religión es un tema mayor en la filosofía de $\mathrm{H}$. Cohen que Benjamin conoce directamente y a través de Rosenzweig. Cohen pretende "una religión de la razón desde las fuentes del judáísmo", tal y como reza el título de su obra póstuma. Y lo hace contraponiendo las posibilidades de una "naturaleza irracional" al Dios de los profetas. Sólo éste posibilita la moral. Para Cohen, pues, cualquier comprensión del mundo que se base en la Naturaleza como punto de partida es un camino equivocado ya que, en ese caso, el entendimiento sólo podría dar vida a fenómenos naturales, convirtiéndoles de esta guisa en "poderes divinos" o deidades. Por eso Cohen opone descaradamente el monoteísmo de la

${ }^{26}$ Ver mi articulo. "W. Benjamin o el primado de la política sobre la historia" en Isegoria, núm. 4, oct. 1991, 49-74. 
revelación al politeísmo del mito. ${ }^{27}$ Lo que Cohen pues pretende es una filosofía ilustrada de la religión que pueda brindar a la teoría del conocimiento de la ciencia unas directrices tomadas directamente del monoteísmo. El objetivo no era bautizar a la ciencia sino "liberarlas del contubernio con el mito" y adentrarlas "en pura doctrina de la eticidad". El monoteísmo, en efecto, plantea la unidad del género humano y, por tanto, permite plantear pensar el problema de la universalidad y la consecuente corresponsabilidad de la acción humana.

Benjamin conoce este planteamiento aunque no lo siga literalmente. Consciente de las reglas de juego de la filosofía traduce el dilema inicial (entre "naturaleza irracional" y "revelación") por el más filosófico entre mito y religión.

Un lugar apropiado para analizar esta relación lo encontramos en el escrito "Schicksal und Charakter" ${ }^{28} \mathrm{El}$ concepto que mejor define al mito sería el de "Schicksal", sino o destino. Pues bien, en la tragedia griega "destino" se descompone en una doble connotación: culpa e infelicidad.

Culpa: frente al destino todo hombre es culpable, antes incluso de que tome cualquier decisión. Dice Benjamin: "El destino es el medio ambiente culpable del viviente. Y tal medio ambiente es el propio de un ser viviente natural, es decir, corresponde a esa aparición todavía no totalmente disuelta, tan oculta a la mirada del hombre que éste no puede hacerse con ella (con la aparición fantasmal); sólo puede, en el mejor de los casos, ocultarse en ella gracias al poderío que ejerce sobre él" ${ }^{29} \mathrm{El}$ destino toma al hombre pues por un ser natural, es decir, por lo que fue antes de que accediera al uso de la libertad; esta reducción al estado natural se hace de una manera vergonzante, como ocultando al hombre su propio ser, para que de esta manera, desprovisto de su libertad y razón, busque cobijo en una fuerza superior que sólo existe porque se le niega ser él mismo.

El hombre es pues culpable como lo es la naturaleza caída a los ojos de su creador. Adviértase que en la tragedia griega 'naturaleza' no tiene la connotación positiva que hoy domina entre nosotros. El dogma de la bondad naturales, según Benjamin, un invento de la comedia. De ahí que el destino del héroe en las tragedias griegas sea la expresión eminente de la caida culpable del hombre en lo natural.

27 B. Witte, Walter Benjamin -der Intellektuelle als Kritiker. Untersucbungen zu seinem Frühwerk. Stuttgart 1976, 47-56.

2* W. B. GS II 1, 171-179.

29. "Schicksal ist der Schuldzusammenhang des Lebendigen. Dieser entpricht der natürlichen Verfassung des Lebendigen, jenem noch nicht restlos aufgelösten Schein, dem der Mensch so entrückt ist, dass er niemals gans in ihn eintauchen, sonclern unter seiner Herrschaft nur in seinem besten Teil unsichtbar bleiben konnte", GS I 175. 
Infelicidad: La culpa se paga con la infelicidad. Hasta tal punto está unida la infelicidad al mito que para ser feliz hay que escapar al embrujo del mito. Y Benjamin recoge el dicho de Hölderlin, "quien llama dioses bienaventurados a los que no tienen destino" ${ }^{30}$ Feliz es el dios que escapa al destino. Y si en algún momento encontramos a algún hombre feliz no es porque se le recompense su inocencia sino como tentación para una más severa inculpación. Bienaventuranza, felicidad, inocencia o justicia sólo se dan fuera de la órbita mítica, lejos pues del campo de influencia del mito.

Esta situación de culpa e infelicidad, independientemente de la libertad del hombre, se institucionaliza en algo así como una culpa genealógica: no sólo el padre paga por una culpa que no ha cometido sino que el hijo tiene que pagar por la culpa de los padres. Nada más extraño al mito que la individualización de la culpa.

Pues bien, dice Benjamin, nada tiene que ver la religión con el destino, $y$, por tanto, con la culpa y la infelicidad propias del mito. En efecto, "un orden cuyos conceptos constitutivos sean los de infelicidad y culpa y en cuyo interior no haya una calle que conduzca a la liberación, un tal orden no puede ser religioso, por mucho que un mal comprendido concepto de culpa haya tenido que ver históricamente con la religión". Y un poco más adelante: "La fundamentación del concepto de carácter (la otra pata del mito) hay que buscarla en un ámbito natural, ámbito que tiene que ver tan poco con la ética o la moral como el destino con la religión".31

Me centraré en un punto: la individualización biblica de la culpa. Benjamin reconocía en el texto anterior que nada se opone tanto al mito como la religión, aunque hay que reconocer que la religión se ha cargado de mitos. Esto es particularmente visible en la individualización de la culpa que, como hemos visto, afecta al núcleo sustantivo de lo que es el mito. Pues bien, en la Biblia es fácil observar cómo durante un largo período de tiempo se repite el convencimiento mítico de la "culpa genealógica": los hijos tienen que pagar por las culpas de los padres. En Exodo, 24, queda patente la fuerza del mito: la culpa y la expiación es el lazo místico que une a las generaciones pasadas y determina la lógica de los acontecimientos en el seno de los pueblos. Con los profetas Ezequiel y Jeremías, sin embargo, se rompe el maleficio mítico: " $¿$ Por qué andáis repitiendo este refrán en la tierra de Israel: "los padres comieron agraces y los hijos tuvieron denteras'? Por mi vida os juro -oráculo del Señor- que nadie volverá a

so "Schicksallos" nennt nicht umsonst die seligen Götter Hölderlin", GS II 1, 174. Ver tumbién R.P. Janz "Mythos und Moderne bei Walter Benjamin" en K. H. Bohrer, Hrsg., Mythos und Modeme, 369.

31 W. B. GS II 1, 176 . 
repetir este refrán en Israel" (Ez. 18, 2-3). Y más adelante: "El que peca es el que morirá; el hijo no cargará con la culpa del padre, el padre no cargará con la culpa del hijo; sobre el justo recaerá su justicia, sobre el malvado recaerá su maldad" (Ez. 18,20).

En ese esforzado intento por descubrir algo así como el código genético de la subjetividad ("Urgeschichte der Subjektivität") este pasaje ofrece una perspectiva radicalmente diferente de la que hemos visto en la Odisea, que era el referente de la DA. El "código genético" de la Odisea hace de la subjetividad humana un laberinto por el que se puede correr pero no escapar; es la simbiosis de mito y logos. Los profetas, por el contrario, separan radicalmente el mito de la libertad. ${ }^{32}$

Nótese finalmente que si el mito se nutre de la culpa y de la infelicidad, Benjamin asocia el de religión con la inocencia ("Kindheit" con "Erlösung"). Esa huella se detecta en su crítica al mundo - mítico- contemporáneo el cual muy consciente de su supuesta superioridad sobre otros mundos antiguos proclama el principio de la "realización de la universalidad", como si su capacidad de generar riquezas posibilitara la felicidad del globo. Ese principio, replica Benjamin, no es tan universal ya que del concepto definitorio de productividad quedan fuera los niños, los locos y los ingenuos.

\section{VIII}

La religión rompe el destino porque reconoce el principio de la libertad $y$, por tanto, de la ética y de la historia. Benjamin profundiza esta línea de reflexión con su teoria de la experiencia.

Ya he dado a entender que el hecho de que Benjamin se niegue a jugar la partida de la verdad en el único tablero "dialéctico" del mito y logos no significa que niegue el carácter mítico de los tiempos actuales, que son cronológicamente tiempos ilustrados. Eso es lo que presenta plásticamente en sus análisis de la experiencia..$^{33}$

No es lo mismo vivir acontecimientos que hacer experiencia de ellos. La prueba está en la generación que entre 1914 y 1918 vivió la primera Gran Guerra: volvieron del campo de batalla mucho más pobres que

\footnotetext{
32 Contra esta interpretación se podria citar un paso de la Odisea. Dice Zeus: ";Oh dioses! ¡De qué modo culpan los mortales a los númenes! Dicen que las cosas malas les vienen de nosotros, y son ellos quienes se atraen con sus locuras infortunios no decretados por el destino" (al principio de la Primera Rapsodia). Esto, sin embargo, más parece un juego retórico pues el argumento de la Odisea es el destino de Odiseo, es decir, los infortunios de una inocente victima de un destino que se le impone.

3 W. I3. GS II 2, 213-219.
} 
fueron. No entendieron nada de lo que vivieron porque carecian de un legado cultural que les permitiera metabolizar el acontecimiento en experiencia. Es una pequeña muestra de los tiempos que corren: "Nos hemos hecho pobres. Hemos ido entregando una porción tras otra de la herencia de la humanidad, con frecuencia teniendo que dejarla en la casa de empeño, por cien veces menos de su valor, para que nos adelantaran la pequeña moneda de lo 'actual'" (II 219).

Son tiempos, por lo que hace a la experiencia, de pobreza o barbarie. Eso tiene que ver con la presencia del mito ya que la pobreza en experiencia se debe a una anulación de la individualidad gracias a la presencia asfixiante de una fuerza extra-humana. El nombre propio del mito contemporáneo sería el del "inconsciente colectivo". Veamos cómo:

La nuestra es una civilización de la imagen, esto es, la aprehensión de la realidad se hace mediante imágenes que conforman un "inconsciente colectivo" que es el que determina la aprehensión que cada cual hace de la realidad. Es casi imposible captar la realidad al margen de los cánones establecidos. Eso es la anulación de la experiencia. Es lo que ocurre cuando uno entra en un cuarto burgués de los años ochenta: "Por muy acogedor que parezca nada tenemos que buscar en él. Nada tenemos que buscar en él porque no hay nada en él, ni un sólo rincón, en el que el morador no haya dejado su huella" (II, 217). Si uno entra en ese cuarto tendrá que acoplarse a las manías del morador; no se le deja espacio para que cambie ni una silla. El precio del imperio de lo colectivo es la anulación del individuo. Para que lo colectivo dé la impresión de ser humano tiene que poner entre paréntesis la humanidad de y en cada individuo. ${ }^{34}$

¿Qué hacer ante una situación así? Contra empobrecimiento de experiencia, pobreza de espíritu; contra barbarie civilizatoria, asumir la humilde condición de "bárbaro". Este programa kenótico, de anonadamiento -que toma tintes franciscanos: "Empezar de nuevo, arreglárselas con poco, construir desde abajo, sin desviar la mirada ni a derechas ni a izquierdas" II 215- tiene como objetivo hacerse con la "totalidad concreta de la experiencia". Para ampliar la experiencia individual más allá del campo acotado por el "inconsciente colectivo" hay que "calar" el engaño de la experiencia ofrecida por el susodicho inconsciente; hay pues que desprenderse de él merced a una conversión que tiene algo de kenótica.

Pues bien, "la religión es precisamente la totalidad concreta de la experiencia", dice al final de "Sobre el programa de la filosofía futura"

34 "Damit das Kollektiv menschliche Züge trage, muss der einzelne unmenschliche tragen können. Die Menschlichkeit muss auf der Ebene des Einzeldaseins preisgegeben werden, un auf der (Elbene) des Kollektivclaseins in Erscheinung su treten" GS II 3, 1102. 
(II, 170). Benjamin ubica la superación del vicio mitológico de la Ilustración en "reservas" (en el sentido habitual de zonas acotadas en espera de su extinción) de la Ilustración. Si la experiencia quiere acceder a zonas ocultas a la realidad producida, si quiere algo más que mera tautología de la realidad producida, tendrá que ir al encuentro de algo no presente en la realidad socialmente producida. A esas "reservas" unas veces lo llama "lo inhumano", otras "el deshecho de la historia", otras "el costo de la historia", "los perdedores", "lo inexpresivo"... En cualquier caso, "motivos" de la religión.

La llave de acceso a la nueva experiencia de la totalidad concreta la tiene el lenguaje. "Kant no advirtió en modo alguno", escribe, "que todo conocimiento filosófico tiene su única expresión en el lenguaje y no en fórmulas y números... Un concepto de experiencia, alcanzado en una reflexión sobre su esencia lingüística permitirá... abarcar regiones insospechadas por Kant, entre ellas, la religión". ${ }^{35}$ Pues bien, su teoría del lenguaje nos dice que sólo hay sentido en la medida en que el lenguaje "comunica", accede al nivel del "lenguaje adámico" que se encuentra a su vez por encima de las convenciones. Es el lenguaje de poetas y místicos. Entiéndase pues que el hecho de que Benjamin ubique en el lenguaje la posibilidad de la experiencia no significa que se desentienda de la experiencia religiosa ya que bíblica es la afirmación de que "la verdad está en la palabra".

Aquí asoma un asunto fundamental en el pensamiento benjaminiano y que recorre toda su vida: la relación entre filosofía y religión, entre materialismo histórico y teología. No entraremos a fondo en él. Bastará dejar una señal del escrito que venimos comentando. "El concepto filosófico de existencia debe legitimarse en el concepto teórico de religión, pero éste, a su vez, debe hacerlo en el concepto radical de la epistemología" (II 171). Benjamin no es un teólogo sino un filósofo que sabe pensar también "desde las fuentes del judaismo", como decía Cohen. Sólo así se puede entender la relación que él establece entre religión y profanidad.

Benjamin, en efecto, apela, por un lado, a la experiencia de la religión para superar la barbarie moderna, pero, por otro, clama contra la pérdida de la profanidad. ¿Cómo se entiende eso?. El "inconsciente colectivo" de la moderna producción social de la realidad (modelidad contemporánea del mito) anula la diferencia entre individuo y colectivo; ahora bien, históricamente la lucha por la emancipación del individuo respecto a lo colectivo ha tomado la forma de la distinción entre sacro y profano. La profanidad ha sido el caldo de cultivo de la individualidad, de ahí que cada 
nuevo intento de diluir lo individual en lo colectivo - como es el caso del moderno "inconsciente colectivo" - acabe negando la distinción entre sacro y profano. De la peligrosidad de esa vuelta atrás da fe el fascismo que era, a sus ojos, "la primera figura de la realización del moderno subrealismo colectivista". ${ }^{36}$

Lo que es llamativo en su reflexión es la relación entre profanidad y religión: ha sido la religión quien ha promocionado la profanidad. Benjamin recoge una tradición interpretativa que explica el fenómeno de la secularidad desde las propias fuentes de la religión. De aquí se deduce que "religión" no se opone a "profano". Son dos realidades que se exigen. Hasta tal punto está Benjamin convencido de esa relación que en el Origen del Drama Barroco Alemán trata de oponerse al nuevo totalitarismo recuperando el impulso protestante contra el poderío teocrático. No se opone la religión a profanidad sino al mito que es el principio de la indistinción y del poderío extrasubjetivo.

\section{$\mathbf{X X}$}

¿Cómo lo hace? ¿En qué consiste la experiencia de la totalidad que posee la religión?

Lo que se opone a religión, entendida como "totalidad concreta de la experiencia", es la "particularidad" de la experiencia, el no poder explanarse el sujeto más allá de lo que el "mito", esto es, el "inconsciente colectivo" le permite. Pues bien, lo que la religión ofrece es una "causalidad mística" en virtud de la cual se hacen presentes los derechos olvidados de generaciones pasadas o de la moderna marginalidad. El reconocimiento de la vigencia de esos derechos (propio de la religión), no contemplados pero no prescritos, presiona y actúa sobre el presente en vista a su reconocimiento moral y político. En ese sentido se habla de una causalidad mistica, sobre cuyo poder no hay que exagerar pues se trata de una "débil fuerza mesiánica". Débil pero es la única dispuesta a enfrentarse a la fuerza del sino.

La presencia en la historia de esa "experiencia concreta de la totalidad" es la ruptura, la interrupción, es decir, se expresa en categorías de tiempo: hacer valer los derechos de los vencidos, sentirnos comunicados con los que descartamos de la comunicación (porque no forman parte de la "comunidad de habla", pues son los que no tienen voz), llevar la experiencia de cada sujeto hasta el encuentro con todos los sujetos concretos, eso significa fundamentalmente interrumpir los tiempos que corren, que son

${ }^{36}$ H. Günther, Walter Benjamin und der humane Marxismus, Walter Verlag, Freiburg, 35 
tiempos del vencedor. En las Tesis, Benjamin recuerda la imagen de los revolucionarios franceses quienes al declinar la tarde y una vez tomada La Bastilla, dispararon contra los relojes de las torres para dar a entender que aquel tiempo se había acabado.

Ahora bien, "interrupción", forma y figura de la nueva experiencia, es un concepto que se opone radicalmente al mito, cuyo tiempo no tiene fin (ya sea bajo la forma del eterno retorno o de la incesante evolución) y se emparenta en primer grado con el judaísmo. El tiempo mesiánico es, en efecto, escatológico (la salvación está al final del tiempo) y apocalíptico (vive de la inminencia de ese fin). Eso explica su extrema beligerancia contra Nietzsche y la oposición de su hombre desvalido al super-hombre nietzscheniano. ${ }^{37}$ Nietzsche, corifeo del mito del tiempo como evolución es un peligro, ya que abandonarse al curso natural de los acontecimientos es hacer el juego al "superhombre"; la apuesta por lo "inhumano", empero, exige poner fin a los tiempos que corren, de ahí que Benjamin evoque la plegaria de Josué pidiendo a Yahvé que parara el sol sobre la ciudad de Gabaon y así disponer de luz suficiente para acabar con sus enemigos (Jos. 10. b12).

\section{$\mathbf{X}$}

La razón anamnética.

Volvamos al polimitismo. La brecha por donde se introduce el polimitismo en la actualidad, convirtiéndose en un tema de nuestro tiempo es el "impasse" teórico de la DA que se ve impotente ante el fracaso de la Ilustración. Pues bien, ese hecho no provoca en el polimitismo el pesimismo antropológico que provocó en los autores del libro. Al contrario, como si el mito ya se hubiera definitivamente aliviado de su carga letal, se ponen a sacar friamente las consecuencias, a saber:

a) el fracaso del proyecto ilustrado acarrea el fin de la filosofía en lo que ésta históricamente más la ha señalado, su pretensión absoluta de verdad;

b) fin igualmente de la pretensión de ligar libertad con verdad: ni la verdad tiene que ser emancipatoria ni la libertad tiene que responder a los intereses de la razón; hay una escisión de esferas: la ciencia dirá lo que es la razón y la libertad consiste en poder elegir libremente;

37 "Tiefste Gegnerschaft gegen Nietzsche: das Verhältnis des Unmenschen zum Übermensch" (GS II 3, 1103), que habría que completarla con las líneas siguientes: "Evolution ist Zerstörung; Einhalt gebieten dem natürlichen Verlauf der Dinge: Gebet an die Sonne von Gibeon" (II 3, 1103). 
c) como ya vio Nietzsche el problema de la filosofía, una vez constatada la complicidad del poder y de la razón, es una teoría del poder que garantice el libre juego de las voluntades. El problema de la filosofía es el de la división de poderes.

Pues bien, Benjamin niega la mayor negando la legitimidad del punto de partida. Puede, en efecto, que la Ilustración sea un mito y viceversa, como se dice en la DA, pero eso no significa renunciar a la filosofia, a sus pretensiones de verdad, a la relación entre verdad y libertad. A lo que hay que renunciar es a la pretensión de una Ilustración satisfecha o totalizante (que es lo que se supone cuando se habla tan fácilmente de Ilustración insatisfecha, Ilustración frustrada, Ilustración fragmentada, etc.) pues eso acaba mal. Lo que ahí se propugna es la realización positiva de la Ilustración y eso es a) formalmente totalitario y b) materialmente particular.

¿Sería posible hablar de una universalidad negativa que no fuera negación de lo particular sino su garantía, que fuera solidaria sin ser totalizante? Conceptos benjaminianos como los de "Konstruktion" y "Monadologie" invitan a no dar por cerrado el intento. 